http://jmscr.igmpublication.org/home/ ISSN (e)-2347-176x ISSN (p) 2455-0450

crossref DOI: https://dx.doi.org/10.18535/jmscr/v8i8.40

\author{
Journal Of Medical Science And Clinical Research \\ IGM Publication \\ An Official Publication of IGM Publication
}

\title{
Various Intraoperative Findings Encountered during Appendectomies- An Observational Study
}

\author{
Authors \\ Karan Singh Thakur ${ }^{1}$, Purnima Patial ${ }^{2 *}$ \\ ${ }^{1}$ Department of Surgery, ZH Mandi, H.P. India \\ ${ }^{2}$ Department of Medicine, ZH Mandi, H.P.India \\ *Corresponding Author \\ Purnima Patial
}

\begin{abstract}
Appendicitis is one of the common diseases faced by the surgeons. Appendectomy is also the most frequently being performed urgent general surgical case. The diagnosis of appendicitis is challenging and requires a skill on the part of the general surgeon to lead to a successful treatment of this disease, thus avoiding the significant morbidity and mortality associated with perforation of appendix. Diagnosis is made on clinical, laboratory and radiological evidences. Standard management is appendectomy. The appendix may be seen in different conditions varying from case to case depending on the duration. Thus quick diagnosis and treatment is helpful in early management and good outcome of the disease. Most of the complications occur when appendix gets perforated. It may simply be found inflamed, but in some cases gets perforated leading localized and even generalized peritonitis. So, Surgeon should be ready to encounter different situations while performing appendix surgery. Surgeon should keep a wide range of possibilities in mind while heading to perform appendectomy. So thorough knowledge is essential for better management and prognosis of the disease.

Keywords: Appendicitis, peritonitis, lump, perforation, mucocele.
\end{abstract}

\section{Introduction}

The appendix is a midgut organ and has been long considered to be a vestigial organ. It may be found in a different locations, with the most common being retrocecal in approximately sixty percent of patients, pelvic in thirty percent, and retroperitoneal in 7-10\% cases. Appendix has its importance in surgery because of its tendency for inflammation, which leads to events of disease called as acute appendicitis. Appendicitis is the commonest cause of acute abdominal pain among young age group. Appendectomy is the most frequently performed abdominal surgery in
Emergency.

Diagnosis is clinical aided with laboratory and radiological investigations. Management is surgical.

\section{Etiology}

There is no single hypothesis to explain cause of appendicitis. Low dietary fiber and high intake of refined carbohydrates may be important. Growth of both aerobic and anaerobic organisms is responsible. Obstruction of appendicular lumen has been widely held responsible. Luminal obstruction with fecolith or a stricture is found in 
majority of cases. Fecolith is made up of thickened faecal material, calcium phosphates, bacteria \& epithelial debris.

\section{Pathology}

Obstruction of the lumen of appendix seems to be essential for gangrene and perforation. Following obstruction, intraluminal pressure increases leading to edema and mucosal ulceration with bacterial translocation to submucosal layer. Further progressive distension leads to venous congestion and ischemia of appendix. With ischemia, bacterial invasion occurs through the muscularispropria and submucosa. Finally, ischemic necrosis leads to gangrenous appendicitis, with free bacterial contamination of peritoneal cavity. The time from onset of obstruction to perforation is variable and may range anywhere from a few hours to a few days. The presentation after perforation is also variable. Alternatively some bowel loops and omentum adheres to inflamed appendix forming phlegmonous mass or paracecal abcess.
Sometimes inflammation settles which leaves a mucous filled structure called as mucocele of appendix. Knowledge of appendicitis is essential because of its risk of perforation and peritonitis.

Risk factors for appendicular perforation are-

1. extremes of age

2. immuno-compromised state

3. diabetics

4. appendicolith

5. pelvic position of appendix

6. previous abdominal surgery

\section{Clinical features}

Symptoms of acute appendicitis include periumbilical pain shifting to right iliac fossa, often associated with anorexia and nausea. Fever may be present. Atypical presentations are often seen in elderly. Clinical signs include pyrexia, tenderness and rebound tenderness. Other signs include Rovsing's sign, obturator sign and psoas sign. Clinical features may vary according to position of appendix, age, obesity and pregnancy.

Differential diagnosis of appendicitis includes-

\begin{tabular}{|l|c|c|c|}
\hline Children & $\begin{array}{c}\text { Adults(in both males } \\
\text { and females) }\end{array}$ & Adult-females & Aged \\
\hline $\begin{array}{l}\text { Meckels } \\
\text { diverticulitis }\end{array}$ & Ureteric colic & PID & Ca colon \\
\hline Intusucception & Enteritis & Endometriosis & Intestinal obstruction \\
\hline Gastroenteritis & Rectus sheath hematoma & Ectopic pregnancy & Diverticulitis \\
\hline HSP & Pancreatitis & Mittelschemerz & Mesentric infarction \\
\hline Mesentric adenitis & Testicular torsion & Pyelonephritis & Leaking aortic aneurysm \\
\hline Pneumonia-Lobar & Perforation peritonitis & $\begin{array}{c}\text { Ovarian cyst } \\
\text { torsion/rupture }\end{array}$ & $\begin{array}{c}\text { Torsion Appendix } \\
\text { epiploicae }\end{array}$ \\
\hline
\end{tabular}

\section{Diagnosis}

The diagnosis of appendicitis is essentially clinical; although, a decision to operate based on clinical grounds alone can lead to the removal of a normal appendix in 15-30 percent of cases. Laboratory reports should be interpreted with caution in cases of suspected appendicitis and should be used to support the clinical picture rather than definitively to prove or exclude the diagnosis. Leukocytosis, often with a "left shift", is present in $90 \%$ of the cases. A normal white blood cell count is found in $10 \%$ of cases, however, and it should not be used as a single test to exclude the presence of appendicitis.

A variety of radiological studies may be used to diagnose appendicitis. These consist of X-rays, computed tomography scanning, ultrasonography and magnetic resonance imaging. Abdominal USG or contrast enhanced CT scan further lowers the chances of negative appendectomy. Contrastenhanced CT abdomen is especially useful in cases where there is a diagnostic dilemma, particularly in the older patients, where other conditions like acute diverticulitis; intestinal 
obstruction and neoplasm are likely differential diagnosis.

Many clinical and lab. based scoring systems have been devised to assist the diagnosis. The most widely used is the Alvarado (MANTRELS) score. A score of 7 or more is strongly goes in favor of acute appendicitis.

\begin{tabular}{|l|c|}
\hline Alvarado/MANTRELS Score & \\
\hline Parameter & Score \\
\hline Symptoms & \\
\hline Migratory pain in RIF & 1 \\
\hline Anorexia & 1 \\
\hline Nausea & 1 \\
\hline Signs & \\
\hline Tenderness in RIF & 2 \\
\hline Rebound tenderness & 1 \\
\hline Elevated temprature & 1 \\
\hline Lab. & \\
\hline Leucocytosis & 2 \\
\hline Shift to left & 1 \\
\hline Total & 10 \\
\hline
\end{tabular}

\section{Treatment}

Conservative treatment may be considered in a patient with limited signs or in those having high risk of surgery (e.g. with multiple comorbidities). However, appendectomy is the standard of care. While there should be no undue delay, all patients, mainly those at risk of serious morbidity, benefit by a short duration of intensive preoperative preparation. When peritonitis is anticipated, intravenous antibiotics to cover gram-negative bacilli as well as anaerobic cocci should be started. Appendectomy may be done by open as well as laparoscopic techniques. Postoperative complications following appendectomy are relatively uncommon and reflect the degree of peritonitis that is present at the time of surgery and con-current diseases that may predispose to complications.

\section{Cases Study}

An Observational study was conducted in the department of surgery of this institution. Study period was of one year. Study was conducted on 70 patients who underwent appendectomies between August 2019 to July 2020.Patients diagnosed clinically, after laboratory tests and radiological confirmation were taken for surgery. Open appendectomy approach was done in all these patients. Different intraoperative findings were encountered in operating room ranging from inflamed appendix to generalized peritonitis.

\section{Observations and Results}

Total 70 patients who were operated in one-year study period, were taken in study group. In 39 patients features only of acute appendicitis i.e. inflammation, distension and edema were found. So majority of patients had acutely inflamed appendix.

In 12 patients appendix was found be perforated. In 10 patients perforation with localized peritonitis was seen. Perforation with generalized peritonitis was seen in 2 patients.

Appendicular lump/mass was found in 5 patients. Appendicular abcess was seen in 7 patients. In 5 patients gangrenous appendicitis was found. Mucocele of appendix was seen in 2 patients.

Overall presentation was as in the table below-

\begin{tabular}{|l|c|c|c|}
\hline S.no. & Finding Intra-op & Number & Percentage (\%) \\
\hline 1 & Appendicitis- inflammation only & 39 & 55.7 \\
\hline 2 & Perforation with localised peritonitis & 10 & 14.3 \\
\hline 3 & Perforation with generalised peritonitis & 2 & 2.9 \\
\hline 4 & Appendicular lump & 5 & 7.1 \\
\hline 5 & Appendicular abcess & 7 & 10 \\
\hline 6 & Gangrenous appendicitis & 5 & 7.1 \\
\hline 7 & Mucocele of appendix & 2 & 2.9 \\
\hline & Total cases & 70 & 100 \\
\hline
\end{tabular}




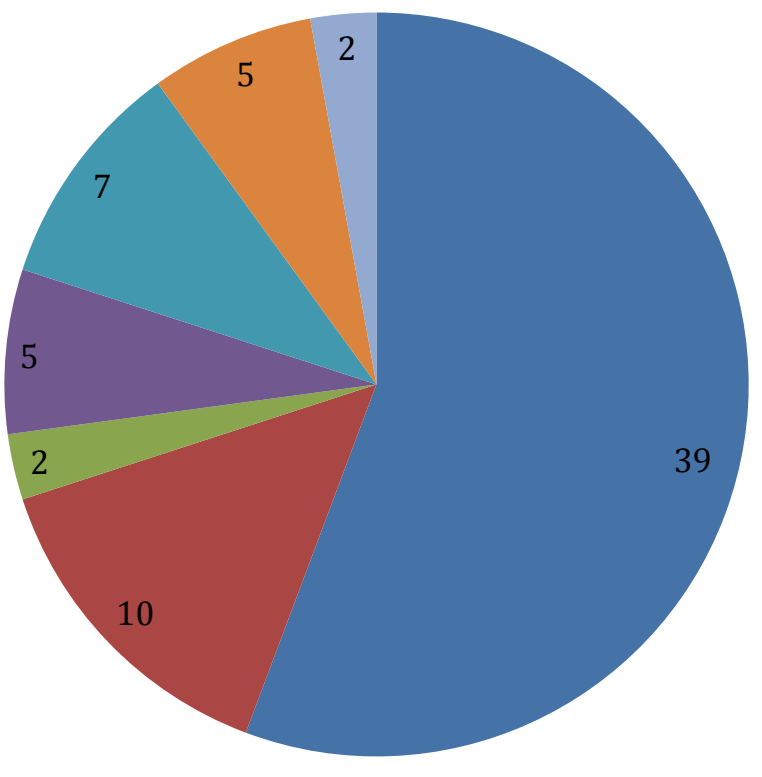

Appendicitis- inflammation only

- Perforation with localised peritonitis

- Perforation with generalised peritonitis

- Appendicular lump

- Appendicular abcess

Gangrenous appendicitis

Mucocele of appendix

Fig. Diagrammatic presentation of the intra-op findings of 70 patients

\section{Discussion}

Appendicitis is the common surgical condition, which can affect any age group, ranging from early childhood to elderly. Diagnosis may be made clinically, aided with laboratory and radiological reports. Standard treatment is surgical. Appendectomy is the most common abdominal surgery being performed. A surgeon may encounter different conditions while performing surgery for appendix. As noticed in this study, acutely inflamed appendix is the most common finding, which is followed by perforated appendix. In majority of perforated appendix, peritonitis is limited to right iliac fossa i.e. localized. Diffuse peritonitis is although seen in very less cases, is associated with increased morbidity. Other findings encountered areappendicular abcess and gangrenous appendicitis. Few cases may show mucocele of appendix. So surgeons should be aware to encounter these situations, which may avoid any unfavourable circumstances.

\section{References}

1. Norman SW, Ronan P, Andrew WM. The vermiform appendix, $27^{\text {th }}$ ed., Bailey and Love Short Practice of Surgery: 12991317.

2. Kumar V, Cotran RS, Robbins SL. Appendix; in Robbins Basic Pathology. $5^{\text {th }}$ edition London: W.B. Saunders 1992; 520.

3. Shrivastava UK, Gupta A, Sharma D. Evaluation of the Alvarado score in the diagnosis of acute appendicitis. Twp Gastroenterol 2004; Oct.- Dec.,25(4): 1846.s

4. Margenthaler JA, Longo WE, Virgo KS, Johnson FE, Oprian CA, Henderson WG, et al. Risk factors for adverse outcomes after the surgical treatment of appendicitis in adults. Ann Surg. 2003;238:59-66.

5. Varadhan KK, Neal KR, Lobo DN. Safety and efficacy of antibiotics compared with appendicectomy for treatment of uncomplicated acute appendicitis: metaanalysis of randomised controlled trials. BMJ. 2012;344:e2156. 
6. Alvarado A. A practical score for acute appendicitis. Ann Emerg Med. 1986 May; 15(5): 557-64.

7. Courtney MT, Daniel B, Mark, E, Kenneth LM, Richmond B. The Appendix, $20^{\text {th }}$ ed. Sabiston textbook of Surgery: 1296-1311. 